\title{
Treatment-refractory obsessive-compulsive disorder: Methodological issues, operational definitions and therapeutic lines
}

\author{
Stefano Pallanti ${ }^{\mathrm{a}, \mathrm{b}, *}$, Leonardo Quercioli ${ }^{\mathrm{b}}$ \\ ${ }^{a}$ Mount Sinai School of Medicine, New York, New York, USA \\ ${ }^{\mathrm{b}}$ Institute of Neuroscience, Florence, Italy
}

Accepted 2 November 2005

Available online 28 February 2006

\begin{abstract}
While controlled trials with SRIs have demonstrated a selective efficacy in obsessive-compulsive disorder (OCD), up to $40-60 \%$ of patients do not have a satisfactory outcome. Non-response to treatment in OCD is associated with serious social disability. There are a large number of nonresponsive patients, and they are difficult to cluster due to ambiguities in diagnostic criteria, possibility of subtypes and a high rate of comorbidity. Moreover, the findings of current studies of "so-called" non-responsive cases are currently non-generalizable because of the lack of an operational definition of non-response. The result has been that a cumulative body of data on a reasonably homogeneous sample of non-responders has not been developed. The aims of the research in this area are to clarify some of the obstacles in defining stages of response and levels of non-response and, through a comprehensive analysis, to propose a systematic nosology for this rather common condition. Better characterization of which patients respond and do not respond to various treatments will enable more accurate clustering of patients, and help facilitate multisite data collection for future research trials. The authors reviewed also the more recent therapeutic pharmacological and psychological lines for the treatment of refractoriness in OCD.
\end{abstract}

(C) 2006 Published by Elsevier Inc.

Keywords: Obsessive-compulsive disorder (OCD); Refractory OCD; Resistant OCD; Treatment response; Treatment non-response

\section{Introduction: non-response is a clinical challenge and theoretical puzzle}

While controlled trials with SRIs have demonstrated a selective efficacy in obsessive-compulsive disorder (OCD), up to $40-60 \%$ of patients do not have a satisfactory outcome (CMI, 1991; Goodman et al., 1992; Jenike and Rauch, 1994; McDougle et al., 1993a,b; Piccinelli et al., 1995; Pigott and Seay, 1999; Rasmussen et al., 1993) and these patients have significant disability and morbidity (Hollander et al., 1996). Since there is

Abbreviations: CBT, cognitive behavioral therapy; CGI, clinical global impression; HQRL, health related quality of life; MAOI, monoamine oxidase inhibitor; NSRI, norepinephrine, serotonin reuptake inhibitor; OCD, obsessivecompulsive disorder; PANDAS, pediatric autoimmune neuropsychiatric disorder associated with streptococcal; SRI, serotonin reuptake inhibitor; SSRI, selective serotonin reuptake inhibitor; Y-BOCS, Yale-Brown ObsessiveCompulsive Scale.

* Corresponding author. Istituto di Neuroscienze, Viale Ugo Bassi 1, Florence 50137, Italy. Tel.: +39055 587 889; fax: +39055 581051 .

E-mail address: s.pallanti@agora.stm.it (S. Pallanti). no operational definition for the concept of "non-response", the labels "non-responder", "treatment-resistant" and "treatmentrefractory" are often used idiosyncratically and synonymously, and all of these terms lack established content validity.

Notwithstanding the lack of precise definitions of response and non-response, several different "next-step" therapeutic strategies and even more complex treatment algorithms have been proposed (Dominguez and Mestre, 1994; Dominguez, 1992; Goodman et al., 1993; Pallanti et al., 2004; Jefferson et al., 1995; Jenike, 1992; March et al., 1997; Rasmussen and Eisen, 1997; Rasmussen et al., 1993). An evidence-based medicine approach would recommend that clinicians integrate their individual clinical expertise with the best available evidence from systematic research (Guyatt et al., 1993, 1994, 1999). A clear definition and limits of the different clinical phases of the disorder represent a basic requirement to trace any therapeutic algorithm. However, in OCD treatment studies, the lack of operational criteria for non-response has prevented the development of a cumulative body of data on a reasonably homogeneous sample of "non-responsive" patients, which has 
created significant limits on the generalizablity of the few existing studies and remains a significant obstacle in the development of useful new studies.

By establishing "stages" of response, a clinician may reliably determine the type of treatment response and thereby be guided toward a next-step strategy (e.g., continue with the treatment, augment the treatment and change the treatment). By establishing "levels of non-response", clinicians and researchers may better characterize the subset of patients according to therapeutic history. With standardized criteria in place, patients previously thought to be totally unresponsive (i.e., "refractory") to treatment may become re-categorized, and patients with a well-defined treatment will become more homogenous and comparable across sites.

The aims of this paper are to clarify some of the obstacles in defining stages of response and levels of non-response and, through a comprehensive analysis, to propose a systematic nosology for this rather common condition.

\section{Measures of treatment response: impact on definition of non-response}

Response criteria markedly impact the percentage of subjects considered responders in various trials and studies that utilize different response criteria and yield very different response rates. The importance of using standardized clinical rating scales in clinical practice as well as in research studies must be stressed. Treatment response should be assessed qualitatively via periodic clinical interviews and the regular use of validated scales. The Yale-Brown Obsessive-Compulsive Scale (Y-BOCS) is the most widely and frequently used instrument to quantify the ongoing severity of OCD symptoms. As approximately $60 \%$ of patients treated with SRIs experience at least a $25-35 \%$ decrease in symptoms on Y-BOCS (Goodman et al., 1992), one of these cut points has typically been operationalized as the criterion for non-response. In an adequate trial of an SRI, a less than $25 \%$ decrease in the Y-BOCS score in patients with at least moderate obsessivecompulsive symptom severity (Goodman, 1999) is usually considered partial response or non-response.

Despite the value of the Y-BOCS in measuring symptom severity, it may not be sensitive to subtle changes, such as a decrease from $5 \mathrm{~h}$ to $3 \mathrm{~h}$ per day of rituals. The Clinical Global Impression (CGI) scale is considered effective in capturing both the larger clinical picture of psychopathology and subtle changes, though it lacks specificity. However, patients with a CGI improvement score of 1 "very much improved" or 2 "much improved" are usually considered responders.

However, when the presence of symptoms does not directly correlate to the severity of disability, it seems questionable to base clinical assessment solely on these two instruments. For instance, no direct correlation exists between the severity of obsessive and compulsive symptoms and severity of distress, especially in the young, where only 1 out of 10 subjects report symptoms to be disturbing (Apter et al., 1996). Subjective well being is a neglected dimension of assessment, only partially considered in the patients' CGI score.
Quality of life has been a recent focus for OCD studies, using measurement instruments such as the Health Related Quality of Life (HQRL) scale; currently, however, only five studies are available (Koran, 2000). Although no consensus exists on how to conceptualize the HRQL, the importance of considering this dimension of patient suffering is evident. If the presence of symptoms has a substantial negative effect on the HRQL score, this score may be a crucial tool for evaluating the degree of recovery following treatment and its assessment should be included in the characterization of non-responsive cases. Psychoeducation might play an important role in improving HRQL in resistant OCD patients and needs to be included in the treatment planning.

\section{Goals, terminology and staging}

In considering the definition of non-response, we must first examine our expectations for treatment. Is recovery a reasonable goal of treatment in OCD patients? Some follow-up studies have reported that after many years some individuals with OCD improve independent of the adequacy of treatment (Orloff et al., 1994; Skoog and Skoog, 1999). Currently, the majority of research consists of short-term clinical trials. Leonard et al. (1993) showed that many children and adolescents with OCD no longer meet criteria for the disorder at follow-up. Long-term studies indicate a range of outcomes from full-blown illness to complete remission. For several other disorders, including major depression, a full response in a clinical trial indicates a return to a condition substantially indistinguishable from a healthy control. In OCD, a return to a state of no illness is a rare clinical event.

Episodic course, with a return to a clinical state of no illness, has also been reported in adults (Perugi et al., 1998; Ravizza et al., 1997). An estimated $5 \%$ of OCD cases have an episodic course (Rasmussen and Eisen, 1997). Therefore, including "recovery" and "remission" in the staging terminology seems reasonable.

Recovery might therefore be considered a realistic target in some patients. Table 1 "stages of response" offers operationa-

Table 1

Stages of response

\begin{tabular}{|c|c|c|}
\hline Stage of response & Stage & Description \\
\hline I & Recovery & $\begin{array}{l}\text { Not at all ill; less than } 8 \text { on } \\
\text { Y-BOCS }\end{array}$ \\
\hline II & Remission & Less than 16 on Y-BOCS \\
\hline III & Full response & $\begin{array}{l}35 \% \text { or greater reduction of } \\
\text { YBOCS and CGI } 1 \text { or } 2\end{array}$ \\
\hline IV & Partial response & $\begin{array}{l}\text { Greater than } 25 \% \text { but less } \\
\text { than } 35 \% \text { YBOCS reduction }\end{array}$ \\
\hline $\mathrm{V}$ & Non-response & $\begin{array}{l}\text { Less than } 25 \% \text { YBOCS } \\
\text { reduction, CGI } 4\end{array}$ \\
\hline VI & Relapse & $\begin{array}{l}\text { Symptoms return } \\
\text { (CGI } 6 \text { or } 25 \% \text { increase in } \\
\text { Y-BOCS from remission score) } \\
\text { after } 3+\text { months of "adequate" } \\
\text { treatment }\end{array}$ \\
\hline VII & Refractory & $\begin{array}{l}\text { No change or worsening with } \\
\text { all available therapies }\end{array}$ \\
\hline
\end{tabular}


lized categories of response to treatment. Since this finding is incompatible with the short-term nature of controlled clinical trials, the duration of both study observations and treatment courses in OCD studies must be re-considered. Additionally, as Orloff et al. (1994) and Skoog and Skoog (1999) are the only two long-term studies of OCD that have been conducted, new long-term prospective and follow-up studies are needed to better guide our expectations for response.

The authors propose establishment of definitions for treatment response in OCD differentiating between "recovery" and "remission", as is proposed by Frank et al. (1991) for depression. We propose recovery to indicate an almost complete and objective disappearance of symptoms, corresponding to YBOCS value of 8 or below. Remission, on the other hand, can indicate a response that reduces symptoms to a minimal level, YBOCS score of 16 or less, based on this the value is below the minimum threshold value to be included in a clinical trial. Because recovery is supposed to occur only in the episodic course, remission should be considered an adequate term to define the most successful outcome in non-episodic course. Both recovery and remission should be considered the highest levels of response to treatment. Such levels of response are fairly rare and a lesser response is the more frequent phenomenon. Currently, values of both a $25 \%$ and $35 \%$ decrease in symptoms in the YaleBrown Obsessive-Compulsive Scale (Y-BOCS) total score are typically defined as the criterion for response (Goodman and Price, 1992). However, one must address the so-called "response to recovery issue" (Stahl, 2000; Angst et al., 1996; Fava et al., 1994; Shea et al., 1996) that hinges on the definition of the "appropriate threshold" for response. Stahl (2000) asks, "Who would accept a 50\% reduction of infectious organism for antibiotic, or 50\% reduction of tumor cells in malignancies, as appropriate outcome targets in these other areas of medicine?" As a partial justification for the modest percentage reduction of YBOCS accepted as "response", the low placebo response rate $(3-5 \%$ decrease in Y-BOCS and NIMH global scale scores) has been invoked (Mavissakalian et al., 1985).

We suggest that, at least for the purposes of research, a $35 \%$ YBOCS reduction could reasonably be considered a full response, between $25 \%$ and $35 \%$ a partial response, and less than $25 \%$ a non-response.

Recovery and remission may have to be defined normatively (normative staging), while all the other stages are defined according to the clinical evaluation of the subjective and symptomatic percentage of amelioration in the patient's own context of living (contextual staging).

Furthermore, a recurrence of symptoms should be judged contextually in relation to an individual's previous clinical condition. Considering the peculiarity of OCD, a disorder where the correlation between symptoms and disability is not that strict, an operational definition of episode is required. As with the definition of an episode in depressive disorder (Frank et al., 1991), that of OCD should be defined as a period lasting at least 2 weeks during which a patient is consistently within the fully symptomatic range on a sufficient number of symp- toms to meet syndromal criteria for the disorder (YBOCS of 16 or above) and clinical impairment.

A drop in CGI Improvement Score to "6" ("much worse" or a $25 \%$ increase in Y-BOCS from the patient's YBOCS score during response) should guide the practitioner toward defining a relapse, a term that corresponds with the return of symptoms satisfying the full syndrome during a remission period (return of the symptoms on an ongoing but sub-clinical disorder). Recurrence describes an entirely new episode; it thus can occur only during a recovery phase and therefore should apply only to the episodic course presentation of the syndrome.

Maintenance and discontinuation studies (Pato et al., 1988, 1990; Leonard et al., 1991; Mundo et al., 1997) show a high rate of relapse $(65-90 \%)$ after acute discontinuation of SRI treatment and a lower degree of response to the same treatment effective for the previous episode (Maina et al., 2001). Both the prevalence of partial response and the high percentage of relapse after drug discontinuation make the OCD clinical course similar to that of psychotic disorders (Emsley, 1999). In determining whether a relapse, exacerbation or new episode has occurred, the timing of return of symptoms, during treatment or after discontinuation, is a relevant consideration. It is unclear whether a relapsed OCD patient, following a previous good response to SRI, but with a subsequent nonresponse, should be considered a "non-responder". Negative and partial responses to treatment are operationalized in Table 1. Perhaps, a distinction between chronic non-response vs. episodic non-response should also be considered.

\section{Methodological considerations: diagnosis, subtypes and comorbidity}

There are numerous theoretical problems implicit in defining response. Among them are issues centering on the complex relationship between what we assume to be the diagnostic core of a disorder, the limits or boundaries of the disorder, and the impact of treatment outcomes on the evolution of diagnostic classifications. Clearly, subtype comorbidity proposals impact response to treat and influence our operational definition.

\section{Diagnosis}

The concept of non-response implies an implicit match between a diagnostic classification and a treatment. This match presupposes the validity of diagnostic instruments and categories. While we rely upon the current diagnostic instruments to define clinical entities, these classifications are often treatmentoriented, correlating with the results of "field trials". In the face of groups of non-responsive patients, we are forced to question whether the current diagnostic categories hold firm or whether a different constellation should be proposed.

According to conventional traditions of psychopathology, the diagnosis of OCD includes the presence of two clinically distinguishable items: obsessions and compulsions. This implies a clear delimitation of both the internal and external boundaries of the terms of definition (Castle and Groves, 
2000). The components that make obsession and compulsion dimensions psychopathological and clearly distinguishable need, however, to be clarified (Leckman et al., 1997). The distinction between obsessions and other psychopathological entities such as worries (Abramowitz and Foa, 1998) and restricted interests, especially in children (Baron-Cohen and Wheelwright, 1999), needs to be explored further. The boundaries between belief, delusional belief and delusion also present some overlap (Abramowitz and Foa, 1998) and need clarification, as does the importance in the OCD construct of awareness, insight and the subjective experience of egodystonia, which have been marginalized from the diagnosis in the DSM-IV (American Psychiatric Association, 1994).

These diagnostic issues affect the limits and range of the categorical diagnosis of obsessive-compulsive disorder. As we clarify true non-responders through our exploration of "matching therapies", current diagnostic boundaries will need to be reassessed.

\section{Subtypes}

Although OCD has long been considered a unitary diagnosis, interest in its potential heterogeneity, as manifested by symptom subgroups, has grown, along with evidence for multidimensionality of OCD symptoms (Summerfeldt et al., 1999).

Illness onset, particularly with respect to gender differences and age of onset, may also be important distinctions in term of treatment appropriateness.

Because reproductive hormones could have specific roles, at least in some specific subtypes such as post-partive onset OCD (Camarena et al., 2001), gender has been suggested as a predictive variable to treatment (Mundo et al., 1999) because brain mechanism in OCD may differ depending on the age at which symptoms are first expressed (Busatto et al., 2001).

Furthermore, late onset could be related to neurological degenerative processes (Weiss and Jenike, 2000), particularly in some at-risk categories of patients, and early onset could be related to a neurodevelopmental process. It also seems reasonable that neuroimaging could be conducted to rule out organic etiology (i.e., post-stroke OCD), before considering an older patient non-responsive to the treatment (i.e., post-stroke OCD) (Scicutella, 2000).

Another issue concerns the distinction between idiopathic and the so-called "acquired" OCD (Chacko et al., 2000) with neurological comorbidity such as Huntington's (Scicutella, 2000) and Sydenham's Chorea, rheumatic fever, bacterial and viral infection, and encephalitis. This has implications for the possible inclusion of diagnostic or serological examinations in the assessment of suspected cases. Positive findings would also require treatment trials beyond SSRIs before considering patients as non-responsive. OCD in Tourette's syndrome, or accompanied by tics, would not be considered non-responsive to only SSRI treatment, but instead considered inadequately treated without combined typical or atypical neuroleptic treatment (e.g., pimozide, haloperidol and risperidone) (McDougle et al., 2000).
While the predictive negative value of neurological soft signs (Hollander et al., 1990) has been questioned (Thienemann and Koran, 1995), another possible subtype has been suggested from the hypothesis of an immune reaction to group A beta hemolytic streptococcal infection, involving antineuronal antibodies, in OCD (Swedo et al., 1998). It is yet to be decided whether this type of OCD should be considered a specific subtype, a special pattern of comorbidity or a new disorder. However, it is clear that pediatric autoimmune neuropsychiatric disorder associated with streptococcal (PANDAS) should be screened when there is a suspicion of streptococcal infection (Swedo et al., 1998; Singer et al., 1998; Peterson et al., 2000) and may be important in evaluating the adequacy and response to treatments such as plasma exchange (Nicolson et al., 2000).

It is unclear whether a differential response for hypothetical subtypes of OCD should be considered in the definition of nonresponse. For example, in patients with severe hoarding symptoms, should dopamine blockers or stimulants be included in a patient's treatment before defining non-response Black et al., 1998; Stein et al., 1997)? In reporting response rates, perhaps the response of cases of severe hoarding behavior, which have a poorer outcome following treatment with serotonin reuptake inhibitors, should be reported separately (Black et al., 1998; Mataix-Cols et al., 1999; Winsberg et al., 1999) from the rates of other non-responsive OCD patients. Perhaps, treatment for these patients should skip "solo" SSRI treatment and start directly with combination with neuroleptics; only after that treatment could the patient be considered nonresponsive to adequate treatment. Adequate treatment utilizing other categories of drugs for specific subtypes should also be evaluated: for example, patients with prevalent symmetry and atypical obsessions or high level of anxiety to treatment may warrant the use of a MAOI (Jenike et al., 1997) or NSRI (Grossman and Hollander, 1996), and/or augmentation with atypical neuroleptics such as risperidone (McDougle et al., 2000) and olanzapine (Bogetto et al., 2000; Koran et al., 2000) before declaring a patient non-responsive. Highly anxious obsessional subjects could also be treated with a combination of benzodiazepines (i.e., clonazepam) and an SSRI (Hewlett et al., 1990, 1992).

\section{Comorbidity}

Another issue in determining non-response to treatment involves the presence of comorbid conditions. While excluding patients with comorbidity from analyses of response to treatment has the advantage of reducing heterogeneity, the results also have less generalizability. Non-responsive patients are more likely to meet criteria for comorbid axis I or axis II disorders and the presence of a specific comorbid condition could be a distinguishing feature in OCD, with influence on the treatment adequacy and outcome. While coexisting depression is generally irrelevant to treatment response (Katz and DeVeaugh-Geiss, 1990; Mavissakalian et al., 1985), a lower response rate has been observed with comorbid chronic tic disorder (Goodman et al., 1992; McDougle et al., 1993a,b) and 
Table 2

Levels of non-response

\begin{tabular}{ll}
\hline Level of non-response & Description \\
\hline I & SSRI or CBT \\
II & SSRI plus CBT \\
III & 2 SSRIs tried plus CBT \\
IV & At least 3 SSRIs tried plus CBT \\
V & At least 3 SRIs (including CMI) plus CBT \\
VI & At least 3 SRIs including clomipramine \\
& augmentation plus CBT \\
VII & At least 3 SRIs including \\
& CMI + CBT + psychoeducation \\
& and other classes of medication \\
& (benzodiazepine, mood \\
& stabilizer, neuroleptic, psychostimulant) \\
VIII & At least 3 SRIs including intravenous \\
& CMI+CBT + psychoeducation \\
IX & At least 3 SRIs including \\
& CMI + CBT + psychoeducation and \\
& other classes of antidepressant agents \\
& (NSRI, MAOI) \\
X & All above treatments, neurosurgery \\
\hline
\end{tabular}

OCD patients with neurological soft signs (Hollander et al., 1990). A comorbid axis II diagnosis of schizotypal, borderline and avoidant personality also seems to predict poorer treatment outcome (Baer et al., 1992), as does obsessive-compulsive personality disorder (Cavedini et al., 1997). While it is still controversial whether comorbid personality disorders change following treatment (Diaferia et al., 1997; Ricciardi et al., 1992), the definition of adequate treatment for OCD patients with a comorbid axis II condition, as well as those without such a condition, should include a CBT trial before concluding nonresponse. While recommendations on treatment choice for OCD (with comorbid disorders and without) and treatment options for non-responders have been addressed by others, including the Expert Consensus Guideline Series (March et al., 1997), the issue being addressed is whether lack of response to the assortment of treatments should define different levels of non-response. While Table 1 "stages of response" is similar to an algorithm for categorizing the effect of the current treatment approach, Table 2 "levels of non-response" enables individual clinicians to decide the "next step" approach. For example, if a partial response is experienced with a treatment, then the current treatment should be reinforced; if there is no response or a negative response to the treatment, then a change of treatment is indicated. Additionally, assigning a category of non-response to patients is important for research. Standardizing the categories of patients enables comparison across studies and in meta-analyses.

\section{Adequate treatment: are SRIs the only adequate trials to define non-response?}

The positive results of placebo-controlled, double-blind studies have led to the designation of several SRIs by the Food and Drug Administration as the only class of drug with an indication to treat OCD. Serotonin dysfunction has been described as playing a role in the pathophysiology of OCD
(Zohar and Kindler, 1992) and strong support for this hypothesis is demonstrated by the selective efficacy of SRIs. To date, adequate trials are considered to be 12-week trials of at least moderate doses of SRIs, that is: clomipramine (150 mg/day), fluoxetine (40 mg/day), sertraline $(100 \mathrm{mg} /$ day), paroxetine (40 mg/day), fluvoxamine (200 mg/day), citalopram (40 mg/day) and venlafaxine (225 mg/day). On the basis of this somewhat tautological conceptualization (OCD responds to SSRIs; therefore, SSRIs are the treatment of choice for OCD; conditions not responsive to SSRIs are not OCD), and because the definition of subtype and the importance of comorbid conditions in the choice of the treatment are not yet accepted, a large portion of treatment strategies follow the line of the 5HT hypothesis (Goodman, 1999). These include: enhancing the serotonergic action of the drugs through dosage increase (even if the clinical outcome does not correlate with plasma level of SRIs such as sertraline and fluoxetine), switching and combining SRIs (Figeuroa et al., 1998; March et al., 1997; Pallanti et al., 1999). Another strategy that has been used to enhance serotonergic action is the use of alternative routes of administration of SRIs such as IV administration (Fallon et al., 1998; Pallanti and Quercioli, 2000). Intravenous treatment with clomipramine has been reported effective for OCD patients with a history of inadequate response to oral treatment with the same drug (Fallon et al., 1998; Koran et al., 1997), and it is, in a large percentage of cases, the first-line treatment in Italy and other European countries for severe cases. Therefore, the route of administration may have an important impact on resistance to treatment and, as such, IV administration should be considered a reasonable treatment choice and used in determining the rate of response of severe cases.

CBT is not only a reasonable first-line therapy, as well as SSRIs, but its application as an augmentation therapy in patients with associated personality disorders (Aubuchon and Malatesta, 1994) or dissociative symptoms (Shusta, 1999) who have been treated with SSRIs but are still symptomatic (Simpson et al., 1999) is particularly indicated. In cases of non-response, CBT must be routinely and consistently integrated with SSRI treatment (Van Noppen et al., 1998), and be used as an augmentation strategy at the various levels of nonresponse (March et al., 1997) in line with the 5-HT hypothesis (Neziroglu et al., 1990).

Drug strategies have gone beyond the serotonergic hypothesis and started to explore alternative biochemical hypotheses. This is an important approach, especially for OCD patients with subtypes or comorbid conditions. For patients with axis II sub-threshold or full-blown personality disorders (e.g., schizotypal) neuroleptic augmentation strategies could be indicated. Examples of other possible matching therapies might be: $\mathrm{OCD}+$ tics $=\mathrm{SSRI}+$ neuroleptic (typical or atypical) $(\mathrm{McDou}-$ gle et al., 2000) and OCD + Anxiety $=$ SSRI + CBT or MAOI (partially supported by Jenike et al., 1997). Would it not be more reasonable that we label a patient a "non-responder" after a matching therapy has failed?

Use of polypharmacotherapy is becoming common in clinical practice (Laird, 1996) but not in clinical trials. This 
results in a discrepancy of non-response: monotherapy, for published studies and polypharmacy for clinical practice. In clinical practice, only polytherapy-treated patients would be included in a sample of non-responders and not monotherapytreated patients. However, if that is so, then we must define response for these treatments. According to the Expert Consensus Guideline Series (March et al., 1997), psychiatrists and psychologists recommend starting with CBT or CBT plus an SSRI, depending on the severity and pattern of comorbidity. Experts generally consider CBT a first-line augmentation strategy and medication augmentation a second-line option. Differences in the chronology of the interventions (if first CBT then SRI or vice versa) should be considered in the definitions of non-response subjects.

\section{Number, type and duration of failed trials}

A good response to a tricyclic such as clomipramine in patients with a diagnosis of depression is in 95\% of cases a predictor of a good response to another primarily serotonergic agent such as amitriptyline (Mattes, 1994; Sacchetti et al., 1994). A few studies comparing different SRIs have shown that we cannot consider the SRIs a homogenous category, such as tricyclics, but as a team with different players; within the category of the so-called SSRIs, the percentage of concordance in treating depression is less than 75\% (Sacchetti et al., 1994; Salzman, 1996). Because a first-line SSRI treatment in OCD has not been established, the choice of first treatment is currently based only on clinician judgment. However, this choice may have a clear effect on the number of trials adopted and later on the designation of a patient as resistant. If an OCD patient does not respond to the first SRI chosen, such as fluoxetine, is that patient a SRI non-responder? Or could the patient have been a full-responder to fluvoxamine as first treatment (Mattes, 1994)? Unfortunately, patients who failed to respond to one or more SRI trials may be less likely than naive patients to respond to further SRI trials (Ackerman et al., 1998). While it is currently unclear whether the sequence of treatment choice truly affects subsequent outcome, motivation to treat with another agent of the same class is typically reduced in exponential progression with each one that fails to elicit response. Further clarification of the definition of response/non-response, together with subsequent support from clinical trials, should ultimately help to address the question of the number, type and sequence of treatments for patients with OCD.

With regard to the duration of treatment, especially for preventing relapse, adequate studies have not been conducted. Prolonged trials should be studied, since naturalistic observation suggests that longer treatment prevents relapse and there is evidence that higher doses for prolonged duration (6 months) have turned $50 \%$ of non-responders into responders. Table 1 is a model of suggested stages of response. Through a methodical progression of research based on definitions of non-response, we may ultimately be able to characterize levels of response, as seen in Table 2. This is based on the expert consensus of our group that parallel those proposed by the group of Michael
Thase (Ninan et al., 2001) in respect of the same staging for depression.

\section{Pharmacological strategies}

Clinical experience supports the conclusion of research studies, which demonstrate a trial of SRIs for long duration (10-12 weeks) and high dose (often the maximum recommended dose) is often required for good efficacy in OCD (Walsh and McDougle, 2004; Pallanti et al., 2004). Often in treating OCD, the clinician at best will experience only alleviation of symptoms, rather than complete remission. Even partial diminution of symptoms, though, can be associated with a significant improvement in quality of life and overall function. In general, if the patient fails to demonstrate a significant response ( $\geq 25 \%$ reduction Y-BOCS) to an adequate trial of a particular agent, the clinician should switch treatment to a different SRI. With a partial response, the clinician is best served to leave the initial agent in place and, assuming the given medication is already titrated to the maximum dose, add an additional agent to augment the effect. Augmentation strategies largely consist of the use of atypical antipsychotics with or without behavioral therapy.

Several studies document the strong relationship between tic disorders and OCD, with evidence of a greater than $35 \%$ prevalence of tic disorders in OCD patients. Given antipsychotics are the standard treatment for Tourette's disorders, McDougle and colleagues (1993a) theorized that the concurrent use of neuroleptics and SRIs in the treatment of OCD patients with tics would be an effective regimen. In a doubleblind, placebo-controlled trial, they demonstrated that haloperidol and fluvoxamine, when used in combination, led to significant improvement in Y-BOCS scores vs. the use of fluvoxamine alone in the patients. Whereas the initial belief was that neuroleptic augmentation preferentially benefited OCD patient with comorbid tics, future research demonstrated OCD patients without evidence of tics also manifested significant improvement with antipsychotics in treating OCD.

The literature to date demonstrates dopamine antagonists to be the most effective agent for augmentation, with the atypical antipsychotic agents being better tolerated than the traditional neuroleptics. It is theorized that, in addition to dopamine blockade, the synergistic action of blockade of $5-\mathrm{HT}_{2 \mathrm{~A}}$ receptors by atypical antipsychotics with the simultaneous inhibition of 5-HT uptake by SRIs leads to overall greater therapeutic efficacy.

McDougle et al. (1995) demonstrated in a double-blind, placebo-controlled trial that risperidone augmentation at an average dose of $2.2 \mathrm{mg} /$ day led to significant improvement in Y-BOCS scores vs. that of an SRI plus placebo. Hollander et al. (2003a) and Pfanner et al. (2000) demonstrated similar findings in double-blind placebo-controlled trials using risperidone to augment SRI treatment in treatment-resistant OCD patients.

In a recent 9-week, double-blind, placebo-controlled, crossover study, Li et al. (2005) compared the benefits of 2-week adjunctive treatments with risperidone, haloperidol and placebo in patients with refractory OCD (DSM-IV criteria; American 


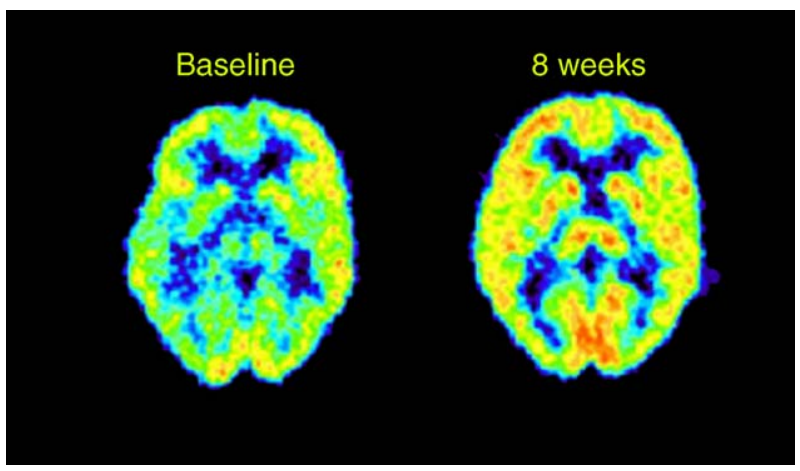

Fig. 1. FDG-PET at baseline and following risperidone treatment.

Psychiatric Association, 1994). They found that, on the YBOCS, both risperidone and haloperidol significantly reduced obsession $(P<0.05)$ when compared with placebo. Neither risperidone nor haloperidol changed neurocognitive function during the 2 -week treatment. Adjunctive risperidone improved obsessions and depressed mood and was well tolerated in patients with SRI-refractory OCD, having all the patients completed the 2 -week risperidone treatment, while $42 \%$ of the subjects on haloperidol terminated treatment early owing to intolerable side effects.

D'Amico et al. (2003) reported efficacy with administration of olanzapine $10 \mathrm{mg}$ /day as augmentation of paroxetine $60 \mathrm{mg} /$ day in an open trial with 21 patients. Bystritsky et al. (2004) demonstrated in a double-blind, placebo-controlled study that a 6-week trial of olanzapine augmentation (5-20 mg/day, mean: $11.2 \mathrm{mg} /$ day) of SRI treatment in refractory OCD led to significant improvement. However, in a double-blind, placebo-controlled trial, Shapira et al. (2004) failed to find similar advantages of olanzapine in OCD fluoxetine-refractory subjects. Denys et al. (2004a) demonstrated in an open-label study that addition of quetiapine (initiated at $75 \mathrm{mg}$ /day and increased to $200 \mathrm{mg}$ /day by week 4) to an SRI for 8 weeks led to a significant decrease in Y-BOCS score in OCD patients previously noted to be treatment-resistant.

Atmaca et al. (2002) demonstrated in a single-blind, placebo-controlled trial that the addition of quetiapine (50-200 $\mathrm{mg} /$ day dose range, with the majority of patients receiving $75-100 \mathrm{mg} /$ day) to SRI therapy in 14 patients with treatment-resistant OCD led to a significant overall improvement in Y-BOCS scores vs. that of the placebo plus SRI group $(n=13)$. Clozapine has been studied as monotherapy in a 10-week, open-label, systematic trial involving patients with treatment-resistant OCD, with the authors reporting no significant improvement in symptoms. No study to date has assessed the efficacy of using clozapine as an augmentation agent in treating OCD, however. Studies involving the use of ziprasidone and aripiprazole as augmenting agents are currently ongoing.

There have been over 30 case reports involving 58 patients of atypical antipsychotics inducing or exacerbating OCD and one prospective study of 113 schizophrenia patients that demonstrated treatment with either olanzapine or risperidone was significantly related $(P<0.01)$ to increased severity of

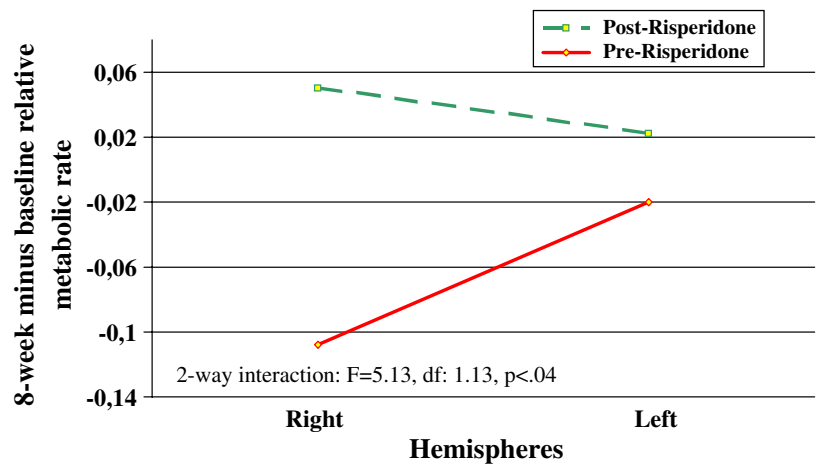

Fig. 2. Effect of risperidone on cingulate gyrus in right and left hemispheres.

OCD symptoms (with olanzapine causing greater exacerbations than risperidone). It is important to note that all of the published reports describing the emergence of obsessivecompulsive symptoms in response to treatment with atypical neuroleptics have involved patients with a primary diagnosis of psychosis.

Our group conducted (Hollander et al., 2003a; Pallanti et al., 2005) a double-blind, placebo-controlled trial to determine the efficacy and tolerability of 8 weeks of risperidone augmentation of serotonin reuptake inhibitor (SRI) in treatmentresistant obsessive-compulsive disorder (failure of at least two SRI trials). Sixteen patients were randomly assigned to augmentation with 8 weeks of either risperidone $(n=10)$ $(0.5-3.0 \mathrm{mg} / \mathrm{day})$ or placebo $(n=6)$ following at least 12 weeks of SRI treatment.

In this study, positron emission tomography (PET) with $18 \mathrm{~F}$-deoxyglucose and magnetic resonance imaging was obtained at baseline and following 8 weeks of either risperidone or placebo (Fig. 1). Four patients on risperidone $(40 \%)$ and none $(0 \%)$ on placebo were responders with both a CGI-I score of 1 or 2 and a Y-BOCS decrease $\geq 25 \%$. Risperidone was generally well tolerated: one subject on risperidone and two on placebo dropped out the treatment. Better Y-BOCS insight score at baseline significantly correlated with a greater CGI-I score at endpoint on risperidone augmentation.

Risperidone treatment was associated with significant increases in relative metabolic rate in the cingulate gyrus (Fig. 2), the striatum (Fig. 3), the prefrontal cortex, especially in the orbital region and the thalamus. Patients with low relative metabolic rates in the striatum and high relative metabolic rates

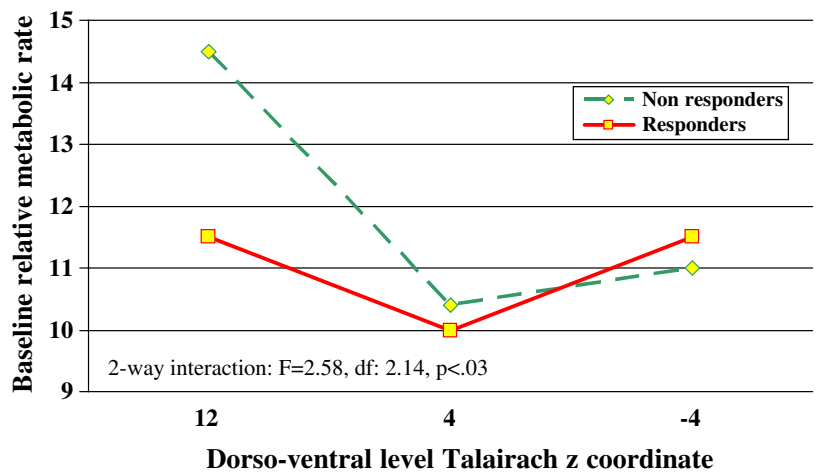

Fig. 3. Effect of risperidone on striatal metabolic rate. 
in the anterior cingulate gyrus were more likely to show a clinical response.

The first conclusion of this study was that Risperidone may be an effective and well-tolerated augmentation strategy in treatment-resistant OCD. The second was that PET results are consistent with a fronto-striatial circuit change related to both dopaminergic and serotonergic systems and with the presence of psychopharmacological subtypes within OCD. While caudate (Saxena et al., 2003) and orbitofrontal hypofunction (Rauch et al., 2002) has been correlated with a response to SRI treatment in OCD, the finding of a predictive value of the striatum in the OCD-resistant sample could represent a hypothesis for a development of a pathophysiologically based categorization of the two conditions: OCD SRI responsive and resistant OCD responsive to neuroleptic augmentation.

Agents such as monoamine oxidase inhibitors, lithium, buspirone, trazodone triiodothyronine, pindolol and benzodiazepines, have been found to be ineffective in open-label studies or placebo-controlled trials as monotherapy or as augmenting agents.

Both fenfluramine and tryptophan have been found effective as augmenting agents in open-label studies, but serious questions concerning their safety have been made both medications unavailable in the US.

Current data seems to indicate that venlafaxine is a reasonable option for monotherapy in treating OCD. Hollander et al. (2003b) administered venlafaxine (mean dose: $232.2 \mathrm{mg}$ /day and range: $37.5-375 \mathrm{mg} /$ day) in a 8-week open-label trial in 39 patients with OCD, 29 of whom were resistant to at least one prior trial of an SRI. Using the Clinical Global Impressions (CGI) scale to assess treatment response, 27 patients $(69.2 \%)$ were noted to have a sustained response, including 22 of the 29 patients $(75.9 \%)$ who failed to response to previous SRIs. Albert et al. (2002) compared venlafaxine $225-350 \mathrm{mg} /$ day with clomipramine 150-225 $\mathrm{mg} /$ day in a 12-week single-blind trial. No statistical difference in efficacy was noted between the two treatment groups and a significantly lesser number of patients treated with venlafaxine reported adverse events $(62 \%$ of patients on venlafaxine vs. $92 \%$ treated with clomipramine, $P=0.002)$. Furthermore, Denys et al. (2004b) demonstrated in a large $(N=150)$ 12-week double-blind, randomized trial that venlafaxine $300 \mathrm{mg} /$ day was equally efficacious as paroxetine $60 \mathrm{mg} /$ day on treating OCD.

The literature contains few trials involving the use of anticonvulsants as monotherapy or augmenting agents in the treatment of OCD. Sodium valproate has been shown to be beneficial only when used as pre-treatment in patients intolerant to standard pharmacotherapy. An 8-week open-label trial of carbamazepine as monotherapy demonstrated no significant therapeutic response, while a 6-week open-label pilot study involving gabapentin as an augmenting agent (mean dose: $2.52 \mathrm{~g} /$ day) in five patients partially responsive to fluoxetine proved to be more promising. However, a 6-week double-blind, placebo-controlled, cross-over trial of gabapentin (titrated to a dose of $3.6 \mathrm{~g} /$ day) augmentation of fluoxetine demonstrated no difference in outcome from placebo, as measured by Y-BOCS, CGI or Hamilton Rating Scale for Anxiety (HAM-A) (Sporn et al., 2001). Carbamazepine and oxcarbazepine have only been described to be successful in case reports as augmenting agents and monotherapy, respectively. Lamotrigine was shown in an open-label study to be ineffective when used to augment sertraline $>200 \mathrm{mg} /$ day or clomipramine $>225 \mathrm{mg} /$ day when administered at doses up to $1000 \mathrm{mg} /$ day for a mean of 47.1 days.

Clomipramine is converted into its less potent subform desmethyl-clomipramine by first pass metabolism in the liver. Theoretically, administering clomipramine intravenously should be more effective in treating OCD, given the ability to bypass first pass metabolism and flood the CNS with higher pulse concentrations of the more potent parent compound. Treatment with intravenous SRIs has been demonstrated to be rapidly effective in a certain subset of OCD patients who are treatment-resistant to oral SRIs. Fallon et al. (1998) demonstrated IV clomipramine to be effective in adults with OCD resistant to or intolerant of oral clomipramine and SSRIs in a double-blind, placebo-controlled trial. Pallanti et al. (2002) administered IV citalopram in an open trial of 39 outpatients who had failed at least two trials of orally administered SRIs, excluding citalopram, and had moderate-to-severe OCD. After 21 days pf IV citalopram, $59 \%$ of the trial subjects demonstrated at least a $25 \%$ decrease in Y-BOCS score.

In a double-blind, pulse-loaded study involving IV clomipramine, Koran et al. (1997) noted that the subjects on IV clomipramine $(n=7)$ demonstrated a more rapid response (decrease in Y-BOCS score by $>25 \%$ by day 4.5 ) than those on oral clomipramine $(n=8)$. There was no significant difference in change in Y-BOCS score, however, between the two study groups at the endpoint of the study ( 8 weeks). Further double-blind trials evaluating the efficacy of IV clomipramine are currently ongoing.

Inositol is a phospholipid that serves as a key metabolic precursor in G-protein-coupled receptors in the brain. Several subtypes of serotonergic, adrenergic and glutamatergic receptors are coupled to phospotidylinositol (PI) hydrolysis. Myoinositol is vital to the resynthesis of PI and, therefore, the sustaining of second-messenger signaling at these receptors. Inositol has been found to be effective monotherapy in at least one double-blind, controlled cross-over trial of OCD. Thirteen OCD patients were randomized to either inositol $18 \mathrm{~g} /$ day or placebo for 6 weeks, with significantly lower Y-BOCS scores noted in the inositol group. Fux et al. (1999) investigated the possible role of inositol as an augmenting agent to SRI treatment in OCD. Ten OCD patients were enrolled in a double-blind, randomized, cross-over study with either inositol $18 \mathrm{~g}$ /day or placebo for 6 weeks in addition to their ongoing SRI treatment. No significant difference was founded between the two groups. Inositol has been noted in other studies to be effective in treating panic disorder and major depressive disorder. The efficacy of inositol in treating OCD, panic and depression does not appear to be solely related to replenishing the pool of PI. Biochemical studies have demonstrated the ability of inositol to alter receptor sensitivity, 
modulate an array of signaling proteins and direct membrane trafficking.

The role of the endogenous opioid system in the pathophysiology of OCD has been postulated by a number of researchers, given some evidence in the literature that opioid antagonists exacerbate OCD symptoms. The use of the opioid agonist tramadol hydrochloride as monotherapy for OCD has, therefore, been investigated in at least one open-label study. Shapira et al. (1997) enrolled seven patients with OCD nonresponsive to treatment with at least one therapeutic trial of an SRI and six subject completed a 6-week period of period of treatment with tramadol at an average dose of $24 \mathrm{mg} / \mathrm{day}$. The average Y-BOCS score was noted to decrease by $26 \%$ over that time period $(z=2, d f=1, P<0.05)$, leading the researchers to conclude that tramadol is a potentially useful alternative medication for treatment-resistant OCD. Subjects enrolled in the study carried a diagnosis of OCD for $>3$ years, had failed an average of 3.4 previous SRI trials and had a Y-BOCS score of $>21$ (median Y-BOCS: 28). All of the 19 study subjects were administered oral morphine sulfate $15-45 \mathrm{mg}$ /day, oral lorazepam $0.5-1 \mathrm{mg} /$ day and placebo in random order in 2-week blocks. Concurrent medications (13 subjects on SRIs, 1 subject on benzodiazepines alone and 1 subject on buproprion alone) were maintained throughout the study. Six study subjects were noted to demonstrate a significant decrease in Y-BOCS score when treated with morphine (median Y-BOCS score when treated with morphine, median Y-BOCS: 17, median decrease 41\%). Koran et al. (2005a) theorized that opiates decrease OCD symptoms via inhibition of glutamate release in the cerebral cortex, disinhibition of serotonergic neurons in the dorsal raphe and increased dopamine transmission in the striatum.

Mirtazapine is a novel antidepressant that blocks presynaptic $\alpha-2$ adrenergic receptors and postsynaptic $5-\mathrm{HT}_{2}$ and $5 \mathrm{HT}_{3}$ receptors, leading to an increase in central norepinephrine and 5-HT. Due to the increase in 5-HT levels, it is expected that patients with OCD would manifest improvement following treatment with mirtazapine. Koran et al. (2001) enrolled 10 patients in an open-label, 10-week trial of mirtazapine as monotherapy. No significant improvement in Y-BOCS scores was appreciated, although only six patients completed the study and doses higher than $>45 \mathrm{mg}$ of mirtazapine were not utilized. For this reason, Koran et al. (2005b) performed a follow-up study that involved 15 treatment-naive patients (mean Y-BOCS score of 27.8) diagnosed with $\mathrm{OCD}>1$ year treated with mirtazapine (mean dose: $54 \mathrm{mg} /$ day) in a 12-week open-label trial. Eight patients were responders (Y-BOCS decrease $>25 \%$ and CGI-I "much improved" or "very much improved", and were then randomized to placebo or mirtazapine in an 8-week double-blind, continuation/discontinuation study. To date, the blind has not been broken in the second phase of the study and, therefore, conclusions have yet to be drawn concerning the efficacy of mirtazapine in OCD. Treatment for OCD typically requires lifelong medication administration, as symptoms of OCD rarely abate over time untreated. Further, some data indicates reinstatement of a medication following relapse can be associated with initial use.
Therefore, it is the unusual situation in which the clinician will feel that it is indicated to taper a patient's medication to off.

\section{Psychotherapy and OCD refractoriness}

Psychotherapy is an important component of treatment for OCD, often underutilized. In his writing, Freud devoted a fair amount of attention to obsessions and compulsions, postulating that they existed on a spectrum ranging from obsessivecompulsive personality disorder to psychosis. Freud suggested the psychoanalytic treatment and it was the accepted treatment for OCD for half a century. At present, there are few accepted data to support such an approach. Behavioral therapy is the current focus of psychotherapy in the treatment of OCD. In OCD cases, behavioral therapy largely exposes to feared stimuli and acts in order to prevent a subsequent response. The therapist prompts the patient to make a hierarchical list of obsession and compulsions, ordered from the least anxiety-provoking symptoms to the most anxiety-provoking. The patient is then exposed to the provocative stimuli repeatedly, discouraging the typical compulsive response. This procedure continues until the stimulus is no longer anxiety-provoking, upon which the therapist moves on to the next stimulus in the hierarchy. At least $25 \%$ of OCD patients are not able to tolerate behavioral therapy due to the stress of being exposed to feared stimuli, while $20 \%$ to $30 \%$ demonstrate little or no improvement.

The significant improvement in OCD with concurrent behavioral therapy and SSRI treatment has been demonstrated by various controlled studies, and two meta-analyses found no differences between the two approaches when used separately. Another meta-analysis appears to demonstrate a superior outcome with behavioral therapy alone vs. that of SSRI treatment. Individuals with OCD treated with behavioral therapy have been found to maintain their gains following discontinuation of treatment, while up to $80 \%$ of patient treated pharmacologically relapse upon treatment discontinuation. With the exception of Albert and colleagues, no well-designed study has until now demonstrated improvement in Y-BOCS scores using behavioral therapy in patients partially responsive to SRI. However, leading experts in OCD generally agree that behavioral therapy should be considered when resistance to SRI therapy appears.

Cognitive therapy of OCD focuses on insight into the overestimation of threat, the excessive concern about controlling thoughts and the over importance of thoughts. The cognitive theory of OCD proposes in fact that obsessional and normal intrusive thoughts differ on how the subject interprets the occurrence and the content. Obsessional patients interpret intrusive cognitions as an indication that they may be responsible for prevention of harm to themselves or another, leading to the feeling of discomfort and the overt or covert neutralizing behaviors. Cognitive therapy seeks to reduce responsibility beliefs, relieving discomfort and minimizing the perceived need to engage in neutralizing rituals. Cognitive therapy is theoretically beneficial in OCD patient unable to comply with exposure therapy with response prevention. Cognitive therapy may be used for treating OCD if behavioral 
therapy fails or is poorly tolerated, the literature currently lending little support to it being efficacious.

Psychotherapy, in some cases of OCD, has to consider the importance to involve the patient's family members, significant others and friends, as the symptoms of OCD often greatly affect (and involve) those close to the patient. Involvement of family members in therapy will help alert those who serve as enablers for the patient's compulsive behavior and, through facilitating this awareness, assist the patient in refraining from this behavior.

\section{Discussion}

It is hard to define "resistance" in OCD. This is due to the various psychopathological, pharmacological and bio-psychosocial elements relevant in term of response to treatment. We purpose criteria and staging of OCD that could be useful in operational definition and practice. Noteworthy, these are pharmaco-centered criteria, and this suggested indirectly that the pharmacological choice and staging of sequential choice are a dominant variable in order to reduce the risk of resistance in OCD. However, a critical question remains whether resistant patients who respond to SRI augmentation/combination pertain to a biological class of OCD patients who respond to antipsychotic augmentation.

There are various reasons to create operational criteria for non-response in OCD. Non-response to treatment in OCD is associated with serious social disability: patient suffering, family suffering and an elevated suicide rate (Hollander et al., 1996). Non-responsive patients are numerous, and their profiles are difficult to cluster due to ambiguities in diagnostic criteria, the possibility of subtypes and high rates of comorbidity. Moreover, the findings of current studies of "so-called" non-responsive cases, which guide the evolution of treatment, are currently non-generalizable because of the lack of an operational definition. Furthermore, there is a significant discrepancy in treatment strategies between academic research (with its general acceptance of linear, monotherapeutic strategies, primarily focused on understanding the disease and treatment process and avoiding interference from too many variables) and general psychiatric clinical practice (in which the clinicians try to maximize response by using as many "variables" as they believe may help), which creates a dichotomy in communication and the direction of research.

These are compelling reasons to clarify the concept of OCD non-response. Our practical objectives, with this paper, are:

(1) To enhance the attention of the clinician to nonresponsive cases.

(2) To encourage the use of instruments in clinical practice and research (such as Y-BOCS) in order to better characterize response/non-response.

(3) To advocate the use of measurements of quality of life and subjective experience of severity and change (e.g., CGI and HRQL) in patient assessment in order to share the therapeutic process with the patient and in order to capture the full clinical picture.
(4) To enable clustering of patients based on reliable and valid conceptual criteria.

(5) To establish a template for non-response "stages" in OCD, thereby increasing the possibility for communication between researchers and clinicians, both for patient care and research purposes.

(6) To facilitate data collection across multiple sites, crossing both cultural and ethnic boundaries, and explore potential biases that may affect diagnostic or treatment criteria.

(7) To encourage the participation of those with expertise from other backgrounds (such as advocacy associations, psychologists, general practitioners, etc.) (Sniderman, 1999) in consensus conferences, as diversity in membership is necessary to improve concordance between different points of view on quality of life issues.

One of the primary aims is the adoption of the "staging of response" as an attempt to define chronological milestones to guide drug changes, dose increase, shifts to other SRIs or to another medication class or augmentation agent (Quitkin et al., 1996), and the search for more refined treatment algorithms.

This purpose is not an end, but a starting point towards moving past anecdotal case reports and implementing treatment strategies developed from evidence-based medicine for partial and non-responsive OCD patients.

The association of other disorders of the striatum with OCD, as well as the results of recent brain imaging studies, suggest that OCD is related to striatal pathology. Abnormalities of the orbitofrontal cortex and cingulate gyrus are also thought to be involved in OCD. The results of the research strongly suggest a familial component to OCD. Genetic polymorphisms of certain serotonin receptor subtypes may play a role in the pathogenesis of OCD. Animal models and clinical research also suggest a role for serotoninergic, glutamatergic and possibly dopaminergic systems in OCD.

As a result, SRIs and antipsychotics have become the mainstay of pharmacologic treatment.

Our study, using risperidone in refractory OCD, confirmed significant metabolic rate increase with administration of this compound in the orbitofrontal and cingulate cortex and in the striatum, two areas found to differ in metabolic rate between normal volunteers and patients with OCD. The study evidenced also that baseline metabolic rate in these areas predicted clinical response to the addition of risperidone to SRI treatment. This evidence was in agreement with studies on the earlier prediction response in affective disorder for SRI treatment (Buchsbaum et al., 1997; Mayberg et al., 1997), in schizophrenia for neuroleptic treatment (Buchsbaum et al., 1992) and in OCD for SRI treatment (Saxena et al., 1999). Data from this study indicated that the effects of medications tend to more likely to be statistically confirmed in areas of the brain, which differ between patients with OCD and normal controls, and in subjects who show significant clinical response. Baseline metabolic response appeared to predict clinical outcome across different groups of patients (affective disorder, schizophrenia and OCD) when similar medications are given. Our results are consistent with a fronto-striatial circuit change 
related to both dopaminergic and serotonergic systems and with the hypothesis of a psychopharmacological subtypes within OCD.

Behavioral psychotherapy has also been shown to be effective in treating $\mathrm{OCD}$, while the role of cognitive therapy in treating OCD is less well defined.

\section{Acknowledgements}

We would like to thank Solvay Pharmaceuticals for their support and Mary Blangiardo for her collaboration.

\section{References}

Abramowitz JS, Foa EB. Worries and obsessions in individuals with obsessivecompulsive disorder with and without comorbid generalized anxiety disorder. Behav Res Ther 1998;36(7-8):695-700.

Ackerman DL, Greenland S, Bystritsky A. Clinical characteristics of response to fluoxetine treatment of obsessive-compulsive disorder. J Clin Psychopharmacol 1998;18(3):185-92.

Albert U, Aguglia E, Maina G, Bogetto F. Venlafaxine versus clomipramine in the treatment of obsessive-compulsive disorder: a preliminary single-blind, 12-week, controlled study. J Clin Psychiatry 2002;63(11):1004-9.

American Psychiatric Association. Diagnostic and statistical manual of mental diseases 4th ed. Washington D.C.: American Psychiatric Press; 1994. DSM-IV.

Angst J, Kupfer DJ, Rosenbaum JF. Recovery from depression: risk or reality? Acta Psychiat Scand 1996;93(6):413-9.

Apter A, Fallon Jr TJ, King RA, Ratzoni G, Zohar AH, Binder M, et al. Obsessive-compulsive characteristics: from symptoms to syndrome. J Amer Acad Child Adolesc Psychiat 1996;35(7):907-12.

Atmaca M, Kuloglu M, Tezcan E, Gecici O. Quetiapine augmentation in patients with treatment resistant obsessive-compulsive disorder: a singleblind, placebo-controlled study. Int Clin Psychopharmacol 2002;17(3): $115-9$.

Aubuchon PG, Malatesta VJ. Obsessive compulsive patients with comorbid personality disorder: associated problems and response to a comprehensive behavior therapy. J Clin Psychiatry 1994;55(10):448-53.

Baer L, Jenike MA, Black DW, Treece C, Rosenfeld R, Greist J. Effect of axis II diagnoses on treatment outcome with clomipramine in 55 patients with obsessive-compulsive disorder. Arch Gen Psychiatry 1992;49(11): $862-866$

Baron-Cohen S, Wheelwright S. Obsessions in children with autism or Asperger syndrome. Content analysis in terms of core domains of cognition. Br J Psychiatry 1999;175:484-90.

Black DW, Monahan P, Gable J, Blum N, Clancy G, Baker P. Hoarding and treatment response in 38 nondepressed subjects with obsessive-compulsive disorder. J Clin Psychiatry 1998;59(8):420-5.

Bogetto F, Bellino S, Vaschetto P, Ziero S. Olanzapine augmentation of fluvoxamine-refractory obsessive-compulsive disorder (OCD): a 12-week open trial. Psychiat Res 2000;96(2):91-8.

Buchsbaum MS, Potkin SG, Siegel Jr BV, Lohr J, Katz M, Gottschalk LA, et al. Striatal metabolic rate and clinical response to neuroleptics in schizophrenia. Arch Gen Psychiatry 1992;49(12):966-74.

Buchsbaum MS, Wu J, Siegel BV, Hackett E, Trenary M, Abel L, et al. Effect of sertraline on regional metabolic rate in patients with affective disorder. Biol Psychiatry 1997;1;41(1):15-22.

Busatto GF, Buchpiguel CA, Zamingnani DR, Garrido GE, Glabus MF, Rosario-Campos MC, et al. Regional cerebral blood flow abnormalities in early-onset obsessive-compulsive disorder: an exploratory SPECT study. J Am Acad Child Adolesc Psychiatry 2001;40(3):347-54.

Bystritsky A, Ackerman DL, Rosen RM, Vapnik T, Gorbis E, Maidment KM, et al. Augmentation of serotonin reuptake inhibitors in refractory obsessivecompulsive disorder using adjunctive olanzapine: a placebo-controlled trial. J Clin Psychiatry 2004;65(4):565-8.
Camarena B, Rinetti G, Cruz C, Gomez A, de La Fuente JR, Nicolini H. Additional evidence that genetic variation of MAO-A gene supports a gender subtype in obsessive-compulsive disorder. Am J Med Gen 2001; 105(3):279-82.

Castle DJ, Groves A. The internal and external boundaries of obsessivecompulsive disorder. Aust N Z J Psychiatry 2000;34(2):249-55.

Cavedini P, Erzegovesi S, Ronchi P, Bellodi L. Predictive value of obsessivecompulsive personality disorder in antiobsessional pharmacological treatment. Eur Neuropsychopharmacol 1997;7(1):45-9.

Chacko RC, Corbin MA, Harper RG. Acquired OCD associated with basal ganglia lesions. J Neuropsychiatry Clin Neurosci 2000;12(2):269-72.

CMI group. Clomipramine in the treatment of patients with obsessivecompulsive disorder The clomipramine collaborative study group. Arch Gen Psychiatry 1991;48(8):730-8.

D'Amico G, Cedro C, Muscatello MR, Pandolfo G, Di Rosa AE, Zoccali R, et al. Olanzapine augmentation of paroxetine-refractory OCD. Prog Neuropsychopharmacol Biol Psychiatry 2003;27(4):619-23.

Denys D, de Geus F, van Megen HJ, Westenberg HG. A double-blind, randomized, placebo-controlled trial of quetiapine addition in patients with OCD refractory to serotonin reuptake inhibitors. J Clin Psychiatry 2004a;65(8):1040-8.

Denys D, van Megen HJ, van der Wee N, Westenberg HG. A double-blind switch study of paroxetine and venlafaxine in OCD. J Clin Psychiatry 2004b;65(1):37-43.

Diaferia G, Bianchi I, Bianchi ML, Cavedini P, Erzegovesi S, Bellodi L. Relationship between obsessive-compulsive personality disorder and obsessive-compulsive disorder. Compr Psychiatry 1997;38(1):38-42.

Dominguez RA. Serotonergic antidepressants and their efficacy in obsessive compulsive disorder. J Clin Psychiatry 1992;52:56-9.

Dominguez RA, Mestre SM. Management of treatment-refractory obsessive compulsive disorder patients. J Clin Psychiatry 1994;55:86-92.

Emsley RA. Partial response to antipsychotic treatment: the patient with enduring symptoms. J Clin Psychiatry 1999;60(Suppl 23): $10-13$.

Fallon BA, Liebowitz MR, Campeas R, Schneier FR, Marshall R, Davies S, et al. Intravenous clomipramine for obsessive-compulsive disorder refractory to oral clomipramine: a placebo-controlled study. Arch Gen Psychiatry 1998;55(10):918-24.

Fava GA, Grandi S, Zielezny M, Canestrari R, Morphy MA. Cognitive behavioral treatment of residual symptoms in primary major depressive disorder. Am J Psychiatry 1994;151(9):1295-9.

Figeuroa Y, Rosenberg DR, Birmaher B, Keshavan MS. Combination treatment with clomipramine and selective serotonin reuptake inhibitors for obsessive-compulsive disorder in children and adolescents. J Clin Adolesc Psychopharmacol 1998;8(1):61-7.

Frank E, Prien RF, Jarrett RB, Keller MB, Kupfer DJ, Lavori PW, et al. Conceptualization and rationale for consensus definitions of terms in major depressive disorder Remission, recovery, relapse, and recurrence. Arch Gen Psychiatry 1991;48(9):851-5.

Fux M, Benjamin J, Belmaker RH. Inositol versus placebo augmentation of serotonin reuptake inhibitors in the treatment of obsessive-compulsive disorder: a double-blind cross-over study. Int J Neuropsychopharmacol 1999;2(3):193-5.

Goodman WK. Obsessive compulsive disorder: diagnosis and treatment. J Clin Psychiatry 1999;60(suppl 18):27-32.

Goodman WK, Price LH. Assessment of severity and change in obsessive compulsive disorder. Psychiatr Clin North Am 1992;15(4):861-9.

Goodman WK, McDougle CJ, Price LH. Pharmacotherapy of obsessivecompulsive disorder. J Clin Psychiatry 1992;53(4 suppl):29-37.

Goodman WK, McDougle CJ, Barr LC, Aronson SC, Pricd LH. Biological approach to treatment-resistant obsessive-compulsive disorder. J Clin Psychiatry 1993;54(6 suppl):16-26.

Grossman R, Hollander E. Treatment of obsessive-compulsive disorder with venlafaxine. Am J Psychiatry 1996;153(4):576-7.

Guyatt GH, Sackett DL, Cook DJ. Users' guides to the medical literature: II How to use an article about therapy or prevention. A. Are the results of the study valid? Evidence-Based Medicine Working Group. JAMA 1993; 270(21):2598-601. 
Guyatt GH, Sackett DL, Cook DJ. Users' guides to the medical literature: II How to use an article about therapy or prevention B What were the results and will they help me in caring for my patients? Evidence-Based Medicine Working Group. JAMA 1994;271(1):59-63.

Guyatt GH, Sinclair J, Cook DJ, Glasziou P. Users' guides to the medical literature: XVI. How to use a treatment recommendation. Evidence-Based Medicine Working Group and the Cochrane Applicability Methods Working Group. JAMA 1999;281(19):1836-43.

Hewlett WA, Vinogradov S, Agras WS. Clonazepam treatment of obsessions and compulsions. J Clin Psychiatry 1990;51(4):158-61.

Hewlett WA, Vinogradov S, Agras WS. Clomipramine, clonazepam and clonidine treatment of obsessive-compulsive disorder. J Clin Psychopharmacol 1992;12(6):420-30.

Hollander E, Schiffman E, Cohen B, Rivera-Stein MA, Rosen W, Gorman JM, et al. Signs of central nervous system dysfunction in obsessive-compulsive disorder. Arch Gen Psychiatry 1990;47(1):27-32.

Hollander E, Kwon JH, Stein DJ, Broatch J, Rowland CT, Himelein CA. Obsessive-compulsive and spectrum disorders: overview and quality of life issues. J Clin Psychiatry 1996;57(Suppl 8):3-6.

Hollander E, Baldini Rossi N, Sood E, Pallanti S. Risperidone augmentation in treatment-resistant OCD: a double blind, placebo controlled study. Int J Neuropsychopharmacol 2003a;6(4):397-401.

Hollander E, Friedberg J, Wasserman S, Allen A, Birnbaum M, Koran LM. Venlafaxine in treatment-resistant obsessive-compulsive disorder. J Clin Psychiatry 2003b;64(5):546-50.

Jefferson JW, Altemus M, Jenike MA, Pigott TA, Stein DJ, Greist JH Algorithm for treatment of obsessive-compulsive disorder. Psychopharmacol Bull 1995;31(3):487-90.

Jenike MA. Pharmacologic treatment of obsessive compulsive disorders. Psychiatr Clin North Am 1992;15:895-919.

Jenike MA, Rauch SL. Managing the patient with treatment-resistant obsessive compulsive disorder: current strategies. J Clin Psychiatry 1994, $55: 11-7$.

Jenike MA, Baer L, Minichiello WE, Rauch SL, Buttolph ML. Placebocontrolled trial of fluoxetine and phenelzine for obsessive-compulsive disorder. Am J Psychiatry 1997;154(9):1261-4.

Katz RJ, DeVeaugh-Geiss J. The antiobsessional effects of clomipramine do not require concomitant affective disorder. Psychiatr Res 1990;31(2): $121-9$.

Koran LM. Quality of life in obsessive-compulsive disorder. Psychiatr Clin North Am 2000;23(3):509-17.

Koran LM, Sallee FR, Pallanti S. Rapid benefit of intravenous pulse loading of clomipramine in obsessive-compulsive disorder. Am J Psychiatry 1997;154(3):396-401.

Koran LM, Ringold AL, Elliott MA. Olanzapine augmentation for treatment-resistant obsessive-compulsive disorder. J Clin Psychiatry 2000; 61(7):514-7.

Koran LM, Quirk T, Lorberbaum JP, Elliott M. Mirtazapine treatment of obsessive-compulsive disorder. J Clin Psychopharmacol 2001;21(5): $537-9$.

Koran LM, Aboujaoude E, Bullock KD, Franz B, Gamel N, Elliott M. Doubleblind treatment with oral morphine in treatment-resistant obsessivecompulsive disorder. J Clin Psychiatry 2005a;66(3):353-9.

Koran LM, Gamel NN, Choung HW, Smith EH, Aboujaoude EN. Mirtazapine for obsessive-compulsive-disorder: an open trial followed by double-blind discontinuation. J Clin Psychiatry 2005b;66(4):515-20.

Laird LK. Issues in the monopharmacotherapy and polypharmacotherapy of obsessive-compulsive disorder. Psychopharmacol Bull 1996; 32(4):569-78

Leckman JF, Grice DE, Boardman J, Zhang H, Vitale A, Bondi C, et al. Symptoms of obsessive-compulsive disorder. Am J Psychiatry 1997;154(7): $911-7$.

Leonard HL, Swedo SE, Lenane MC, Rettew DC, Cheslow DL, Hamburger $\mathrm{SD}$, et al. A double-blind desipramine substitution during long-term clomipramine treatment in children and adolescents with obsessivecompulsive disorder. Arch Gen Psychiatry 1991;48(10):922-7.

Leonard HL, Swedo SE, Lenane MC, Rettew DC, Hamburger SD, Bartko JJ, et al. A 2- to 7-year follow-up study of 54 obsessive- compulsive children and adolescents. Arch Gen Psychiatry 1993; 50(6):429-39.

Li X, May RS, Tolbert LC, Jackson WT, Flournoy JM, Baxter LR. Risperidone and haloperidol augmentation of serotonin reuptake inhibitors in refractory obsessive-compulsive disorder: a crossover study. J Clin Psychiatry 2005;66(6):736-43.

Maina G, Albert U, Bogetto F. Relapses after discontinuation of drug associated with increased resistance to treatment in obsessive-compulsive disorder. Int Clin Psychopharmacol 2001;16(1):33-8.

March JS, Frances A, Kahn DA, Carpenter D, editors. The expert consensus guideline series: treatment of obsessive-compulsive disorder, 58 (suppl 4). J Clin Psychiatry; 1997. p. 1-72.

Mtaix-Cols D, Rauch SL, Manzo PA, Jenike MA, Baer L. Use of factoranalyzed symptoms dimension to predict outcome with serotonin reuptake inhibitors and placebo in the treatment of obsessive-compulsive disorder. Am J Psychiatry 1999;156(9):1409-16.

attes JA. Fluvoxamine in obsessive-compulsive nonresponders to clomipramine or fluoxetine. Am J Psychiatry 1994;151(10):1524.

Mavissakalian M, Turner SM, Michelson L, Jacob R. Tricyclic antidepressants in obsessive-compulsive disorder: antiobsessional or antidepressant agents? II. Am J Psychiatry 1985;142(5):572-6.

Mayberg HS, Brannan SK, Mahurin RK, Jerabek PA, Brickman JS, Tekell JL, et al. Cingulate function in depression: a potential predictor of treatment response. Neuroreport 1997;3;8(4):1057-61.

McDougle CJ, Goodman WK, Leckman JF, Barr LC, Heninger GR, Price LH. The efficacy of fluvoxamine in obsessive-compulsive disorder: effects of comorbid chronic tic disorder. J Clin Psychopharmacol 1993a;13(5):354-8.

McDougle CJ, Goodman WK, Leckman JF, Price LH. The psychopharmacology of obsessive compulsive disorder Implications for treatment and pathogenesis. Psychiatr Clin North Am 1993b;15(4):749-66.

McDougle C, Fleischmann R, Epperson N, Wasylink S, Leckman JF, Price LH. Risperidone addition in fluvoxamine-refractory obsessive-compulsive disorder: three cases. J Clin Psychiatry 1995;56:11.

McDougle CJ, Epperson CN, Pelton GH, Wasylink S, Price LH. A doubleblind, placebo-controlled study of risperidone addition in serotonin reuptake inhibitor-refractory obsessive-compulsive disorder. Arch Gen Psychiatry 2000;57(8):794-801.

Mundo E, Bareggi SR, Pirola R, Bellodi L, Smeraldi E. Long-term pharmacotherapy of obsessive-compulsive disorder: a double blind controlled study. J Clin Psychopharmacol 1997;17(1):4-10.

Mundo E, Bareggi SR, Pirola R, Bellodi L. Effect of acute intravenous clomipramine and antiobsessional response to proserotonergic drugs: is gender a predictive variable? Biol Psychiatry 1999;45(3):290-4.

Neziroglu F, Jeffrey Steele, Jose A, Yaryura-Tobias, Hitri A, Diamond B. Effect of behavior therapy on serotonin level in obsessive-compulsive disorder. Psychiatry: A World Perspectivevol. 3; 1990. p. 707-10.

Nicolson R, Swedo SE, Lenane M, Bedwell J, Wudarsky M, Gochman P, et al. An open trial of plasma exchange in childhood-onset obsessive-compulsive disorder without poststreptococcal exacerbations. J Am Acad Child Adolesc Psychiatry 2000;39(10):1313-5.

Ninan P, Rush J, Altshuler L, Demitrack M, Entsuah R, Gorman J, et al. Remission and demonstrating efficacy in clinical trials. American college of Neuropsychopharmacology, 40th annual meeting December 9-12, Waikoloa, Hawaii, scientific abstract; 2001. p. 93.

Orloff LM, Battle MA, Baer L, Ivanjack L, Pettit AR, Buttolph ML, et al. Long-term follow-up of 85 patients with obsessive-compulsive disorder. Am J Psychiatry 1994;151(3):441-2.

Pallanti S, Quercioli L. Intravenous citalopram in obsessive-compulsive patients non-responders to SRI. ACNP 39th annual meeting abstract book; 2000. p. 165.

Pallanti S, Quercioli L, Paiva RS, Koran LM. Citalopram for treatment-resistant obsessive-compulsive disorder. Eur Psychiatry 1999;14(2):101-6.

Pallanti S, Quercioli L, Koran LM. Citalopram intravenous infusion in resistant obsessive-compulsive disorder: an open trial. J Clin Psychiatry 2002;63(9): 796-801.

Pallanti S, Hollander E, Goodman WK. A qualitative analysis of nonresponse: management of treatment-refractory obsessive-compulsive disorder. J Clin Psychiatry 2004;65(Suppl 14):6-10. 
Pallanti S, Buchsbaum M, Hollander E. Neuroleptic augmentation in OCD: clinical and neuroimaging of risperidone. Presented at: 13th AEP Congress, Munich (DE) 2-6/4/2005; 2005.

Pato MT, Zohar-Kadouch R, Zohar J, Murphy DL. Return of symptoms after discontinuation of clomipramine in patients with obsessive-compulsive disorder. Am J Psychiatry 1988;145(12):1521-5.

Pato MT, Hill JL, Murphy DL. A clomipramine dosage reduction study in the course of long-term treatment of obsessive-compulsive disorder patients. Psychopharmacol Bull 1990;26(2):211-4.

Perugi G, Akiskal HS, Gemingnani A, Pfanner C, Presta S, Milanfranchi A, et al. Episodic course in obsessive-compulsive disorder. Eur Arch Psychiatry Clin Neurosci 1998;248(5):240-4.

Peterson BS, Leckman JF, Tucker D, Scahill L, Staib L, Zhang H, et al. Preliminary findings of antistreptococcal antibody titers and basal ganglia volumes in tic, obsessive-compulsive, and attention deficit/hyperactivity disorders. Arch Gen Psychiatry 2000;57(4):364-72.

Pfanner C, Marazziti D, Dell'Osso L, Presta S, Gemignani A, Milanfranchi A, et al. Risperidone augmentation in refractory obsessive-compulsive disorder: an open-label study. Int Clin Psychopharmacol 2000;15(5):297-301.

Piccinelli M, Pini S, Bellantuono C, Wilkinson G. Efficacy of drug treatment in obsessive-compulsive disorder A meta-analytic review. Br J Psychiatry 1995;166(4):424-43.

Pigott TA, Seay SM. A review of the efficacy of selective serotonin reuptake inhibitors in obsessive-compulsive disorder. J Clin Psychiatry 1999;60(2):101-6.

Quitkin FM, McGrath PJ, Stewart JW, Ocepek-Welikson K, Taylor BP, Nunes E, et al. Chronological milestones to guide drug change When should clinicians switch antidepressants. Arch Gen Psychiatry 1996;52(9):785-92.

Rasmussen SA, Eisen JL. Treatment strategies for chronic and refractory obsessive-compulsive disorder. J Clin Psychiatry 1997;58(Suppl 13):9-13.

Rasmussen SA, Eisen JL, Pato MT. Current issues in the pharmacological management of obsessive-compulsive disorder. $\mathrm{J}$ Clin Psychiatry 1993;54:4-9.

Ravizza L, Maina G, Bogetto F. Episodic and chronic obsessive-compulsive disorder. Depress Anxiety 1997;6(4):154-8.

Rauch SL, Shin LM, Dougherty DD, Alpert NM, Fischman AJ, Jenike MA. Predictors of fluvoxamine response in contamination-related obsessive compulsive disorder: a PET symptom provocation study. Neuropsychopharmacology 2002;27(5):782-91.

Ricciardi JN, Baer L, Jenike MA, Fischer SC, Sholtz D, Buttolph ML. Changes in DSM-III-R axis II diagnoses following treatment of obsessive-compulsive disorder. Am J Psychiatry 1992;149(6):829-31.

Sacchetti E, Conte G, Guarneri L. Are SSRI antidepressants a clinically homogeneous class of compounds? Lancet 1994;344(8915):126-7.

Salzman C. Heterogeneity of SSRI response. Harvard Rev Psychiatry 1996;4(4):215-7.

Saxena S, Brody AL, Maidment KM, Dunkin JJ, Colgan M, Alborzian S, et al. Localized orbitofrontal and subcortical metabolic changes and predictors of response to paroxetine treatment in obsessive-compulsive disorder. Neuropsychopharmacology 1999;21(6):683-93.

Saxena S, Brody AL, Ho ML, Zohrabi N, Maidment KM, Baxter Jr LR. Differential brain metabolic predictors of response to paroxetine in obsessive-compulsive disorder versus major depression. Am J Psychiatry 2003;160(3):522-32.

Scicutella A. Late-life obsessive-compulsive disorder and Huntington's disease. J Neuropsychiatry Clin Neurosci 2000;12(2):288-9.
Shea MT, Leon AC, Mueller TI, Solomon DA, Warshaw MG, Keller MB. Does major depression result in lasting personality change? Am J Psychiatry 1996;153(11):1404-10.

Shapira NA, Keck Jr PE, Goldsmith TD, McConville BJ, Eis M, McElroy SL. Open-label pilot study of tramadol hydrochloride in treatmentrefractory obsessive-compulsive disorder. Depress Anxiety 1997;6(4): $170-3$.

Shapira NA, Ward HE, Mandoki M, Murphy TK, Yang MC, Blier P, et al. A double-blind, placebo-controlled trial of olanzapine addition in fluoxetinerefractory obsessive-compulsive disorder. Biol Psychiatry 2004;1;55(5): $553-5$.

Shusta SR. Successful treatment of refractory obsessive-compulsive disorder. Am J Psychother 1999;53(3):377-91.

Simpson H, Gorfinkle K, Liebowitz M. Cognitive-behavioral therapy as an adjunct to serotonin reuptake inhibitors in obsessive-compulsive disorder: an open trial. J Clin Psychiatry 1999;60:9.

Singer HS, Giuliano JD, Hansen BH, Hallett JJ, Laurino JP, Benson M, et al. Antibodies against human putamen in children with Tourette syndrome. Neurology 1998;50(6):1618-24.

Skoog G, Skoog I. A 40-year follow-up of patients with obsessive-compulsive disorder. Arch Gen Psychiatry 1999;56(2):441-2.

Sniderman AD. Clinical trials, consensus conferences, clinical practice. The Lancet 1999;35:4327-30.

Sporn J, Smith M, Jean-Mary J, Greenberg B, Cora-Locatelli G, Murphy D. A double-blind, placebo-controlled trial of gabapentin augmentation of fluoxetine for treatment of obsessive-compulsive disorder. Poster presented at NCDEU 41st annual meeting, Phoenix (Arizona) May 28-31.

Stahl S. The issue of functional versus symptomatic recovery in depression. J Clin Psychiatry 2000;61:447-8.

Stein DJ, Bouwer C, Hawkridge S, Emsley RA. Risperidone augmentation of serotonin reuptake inhibitors in obsessive-compulsive and related disorders. J Clin Psychiatry 1997;58(3):119-22.

Summerfeldt LJ, Richter MA, Antony MM, Swinson RP. Symptom structure in obsessive-compulsive disorder: a confirmatory factor-analytic study. Behav Res Therapy 1999;37(4):297-311.

Swedo SE, Leonard HL, Garvey M, Mittleman B, Allen AJ, Perlmutter S, et al. Pediatric autoimmune neuropsychiatric disorders associated with streptococcal infections: clinical description of the first 50 cases. Am J Psychiatry 1998;155(2):264-71.

Thienemann M, Koran LM. Do soft signs predict treatment outcome in obsessive-compulsive disorder? J Neuropsychiatry Clin Neurosci 1995;7(2):218-22.

Van Noppen BL, Pato MT, Marsland R, Rasmussen SA. A time-limited behavioral group for treatment of obsessive-compulsive disorder. J Psychother Pract Res 1998;7(4):272-80.

Walsh KH, McDougle CJ. Pharmacological augmentation strategies for treatment-resistant obsessive-compulsive disorder. Expert Opin Pharmacother 2004;5(10):2059-67.

Weiss AP, Jenike MA. Late-onset obsessive-compulsive disorder: a case series. J Neuropsychiatry Clin Neurosci 2000;12(2):265-8.

Winsberg ME, Cassic KS, Koran LM. Hoarding in obsessive-compulsive disorder: a report of 20 cases. J Clin Psychiatry 1999;60(9):591-7.

Zohar J, Kindler S. Update of the serotonergic hypothesis of obsessivecompulsive disorder. Clin Neuropharmacol 1992;15(Suppl 1 PT A): $257 \mathrm{~A}-8 \mathrm{~A}$. 